\title{
Research on Fatigue Driving State based on Multi-source Information Fusion
}

\author{
Jiang Xinyue, Jiang Ming, Shen Hui, Chen Jingxin* \\ College of Mechanical Engineering, Yangzhou University, Yangzhou 225000, China \\ *Corresponding Author: 865969822@qq.com
}

\begin{abstract}
To improve the accuracy and acceptance of driver fatigue recognition in practical applications and vehicle safety, by comparing the driver's face expression features, car driving characteristics and other multi-source fatigue information collection and driver acceptance, a fatigue driving state recognition scheme based on multi-source information fusion is proposed. The scheme includes two cameras and a steering angle sensor. The front-up camera collects eye position, frequency of blinks, frequency of glancing, staring time, and other indicators; The side camera collects the information of driver's head position; the steering angle sensor collects the steering wheel angle data. The fatigue driving state of the driver is classified and defined by a multi-source information detection method such as pupil characteristics, head tilt angle and steering wheel angle data. Through a comparison of Test Schemes for fatigue driving, it is concluded that the simulation driving experiment scheme has the best comprehensive index in terms of safety, economics, driving state fit and so on. Based on the work above, an experimental platform for fatigue driving recognition was established.
\end{abstract}

Keywords: fatigue driving, face expression feature, multi-source information, fatigue recognition, experimental platform.

\section{Introduction}

Traffic accidents are one of the serious social problems in the world. According to the World Health Organization (WHO), casualties caused by road traffic accidents by 2030 will be one of the main causes of human death and injury. According to statistics on traffic accidents in many countries, fatigue driving is one of the most important causes of traffic accidents ${ }^{(1)}$. There are at least 100,000 traffic accidents caused by fatigue driving in the United States each year, and $10 \%$ of accidents caused by fatigue driving in traffic accidents in the United Kingdom. Accidents caused by fatigue driving account for $20.6 \%$ of casualties in France. Therefore, the research on drivers fatigue detection is of great significance.

Many countries have begun research and development of fatigue driving detection and Driver Fatigue Monitor System. S.A.M (Steering Attention Monitor) is developed by Digital Installations of the United States that monitors abnormal movement of the steering whee ${ }^{(2)}$. The AWAKE project of European Union realizes driver fatigue classification by information fusion technology and develops fatigue driving early warning system by sound, light flashing and seat belt vibration ${ }^{(3)}$.

Chinese research on fatigue driving started late. The JLUVA-DFWS system developed by Jilin University infers the driver's mental state based on eye and lip opening, and give warning message if the driver appears fatigue state during driving. BAWS of BYD infers the driver's fatigue status based on the driver's physiological signals, alerts the driver and takes action.

The acceptance of the testing equipment by the driver in practical applications is not taken into account in the current fatigue detection research. And the results of fatigue detection are highly correlated with the environment. However, some experimental platforms of fatigue driving in Chinese universities simulating the interior environment are different from the real driving environment.

Therefore, this paper studies the fatigue driving state based on multi-source Information fusion. The driver drives in the modified abandoned vehicle in front of the screen showing traffic information. Based on the characteristics of driver's pupil from the front-up camera, the information of 
driver's head position from the side camera, and the steering wheel angle data from the steering angle sensor, the driving state of the driver is discriminated.

\section{Analysis of Schemes for Collection of Fatigue Information}

Nowadays, the method used to detect driver's fatigue mainly includes three kinds. The first one is a method based on examin ing driver's physiological information; the second is a method based on the driver's behavior; the third one is a method based on monitoring the situation of the motor vehicle. In the first method, the mechanism used to detect fatigue state involves collecting physiological signals mainly such as electrical brain signals, heartbeat and other physiological indicators in order to distinguish whether driver is drowsy or not. The second method uses equipment to monitor driver's eyes, position of head and other indicators. The third method uses signals such as variation of motional orbit, steering wheel angle and other information from vehicle to conduct data analysis hence supervise driver's fatigue state.

Electroencephalogram (EEG) has been frequently used in the study of fatigue driving. EEG considered as the most accurate and credible indicator for fatigue detection, is the "golden indicator" for fatigue detection ${ }^{(4)}$. When fall into fatigue, $\delta$ wave and $\theta$ wave increase, while $\alpha$ wave and $\beta$ wave decrease ${ }^{(5-6)}$. Driver's head wears signal acquisition device, with high dependency and low acceptance. It not only makes driver feel uncomfortable but also influences driving ability of driver. It is not suitable for practical application of fatigue driving detection. With high credibility and little change to the car therefore it is suitable as a reference parameter.

Through electrocardiogram (ECG) equip ment get many different information of ECG Where, the heart rate and the variation of heart rate are significant physiological criteria for gauging the fatigue state ${ }^{(7-8)}$. As the driver's fatigue increases, the ratio of low frequency and high frequency of the ECG is gradually reduced ${ }^{(9-10)}$. But all censors define biological index must stick electrodes on the body, with high dependency and low acceptance. With high credibility and few changes to the car therefore it is suitable as a reference parameter.

The degree of eyelid's closure expresses clearly human's fatigue. Therefore, driver's fatigue recognition methods relied on this characteristic have fast result and high accuracy. With low dependency, high acceptance and accuracy, based on the characteristics of driver's pupil from the front-up camera, the driver's fatigue can be gauged. There is few changes in the body, such as the installation of cameras and control systems without changing the core components that affect safe driving.

With this method through driver's head position in driving process to determine the driver whether is fatigued or not. The head position relates to the state of fatigue. When driver is fatigued, his head position will change. Nodding or shaking will appear or even drowse. This information can be used as the basis to determine the fatigue. Based on the information of driver's head angle from the earplug, fatigue driving can be identified exactly. The driver can accept it within the constraints and the installation of the control system makes small changes to the car.

When the driver starts to feel drowsy due to his attention was distracted, slow reaction movement is not flexible, etc., and possibility leads to lane departure. Base on the information from the front-up camera about the movement of vehicle such as the variation of motional orb it, position, etc., the driver's fatigue can be gauged without change of the core components that affect driving. It has minimal interference with the driver with low dependency and high acceptance. However, it is difficult in the evening because of low definition of white lines. Affected by the environment, the accuracy is low.

When the driver is fatigued, the reaction is not flexible, the movement is slow or in dangerous situations, the driver adjusts the steer with big amplitude. Therefore we can use this feature to determine the driver's fatigue. Based on the steering wheel angle data easily to be extracted from the steering angle sensor at the steering column, the driver's fatigue can be gauged. It has minimal interference with the driver with low dependency and high acceptance. However, it needs to change the steering wheel, which is the core component of driving. It is greatly affected by factors such as vehicle characteristics, driving habits and road environment. Other fatigue driving detection methods need to be combined because of low accuracy.

The paper analyzes and compares the schemes and characteristics of six kinds of collection of fatigue information. The results are shown in Table 1. 
Table 1. Comparis on of fatigue information collection Schemes.

\begin{tabular}{|c|c|c|c|c|}
\hline & \multirow{2}{*}{$\begin{array}{c}\text { fatigue } \\
\text { information }\end{array}$} & \multicolumn{2}{|c|}{ Characteristic } & \multirow[b]{2}{*}{ Comment } \\
\hline & & Dependence & $\begin{array}{c}\text { Difficulty in } \\
\text { modifying the car }\end{array}$ & \\
\hline 1 & $\mathrm{EEG}^{(4-6)}$ & 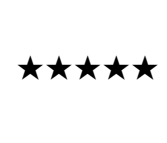 & 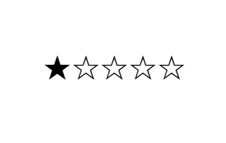 & $\begin{array}{l}\text { As } \\
\text { reference } \\
\text { parameter }\end{array}$ \\
\hline 2 & $\mathrm{ECG}^{(7-10)}$ & 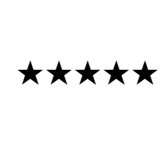 & 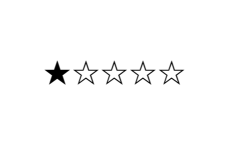 & $\begin{array}{l}\text { As } \\
\text { reference } \\
\text { parameter }\end{array}$ \\
\hline 3 & $\begin{array}{l}\text { Pupil } \\
\text { Characteristics } \\
\text { (11) }\end{array}$ & 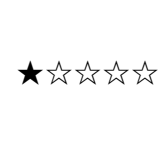 & 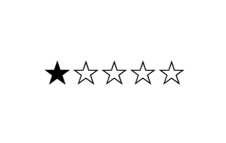 & $\begin{array}{l}\text { High } \\
\text { acceptance }\end{array}$ \\
\hline 4 & $\begin{array}{l}\text { The head } \\
\text { position }^{(12)}\end{array}$ & 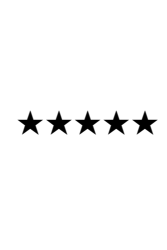 & 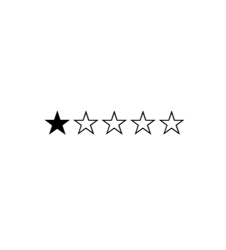 & $\begin{array}{l}\text { The driver } \\
\text { can accept } \\
\text { it within } \\
\text { the } \\
\text { constraints }\end{array}$ \\
\hline 5 & $\begin{array}{l}\text { The steering } \\
\text { wheel angle } \\
\text { data }^{(13-14)}\end{array}$ & 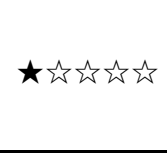 & 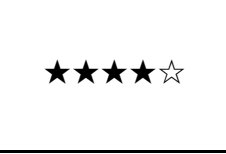 & $\begin{array}{l}\text { High } \\
\text { acceptance }\end{array}$ \\
\hline 6 & $\begin{array}{l}\text { The movement } \\
\text { of vehicle }^{(15)}\end{array}$ & 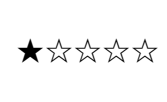 & 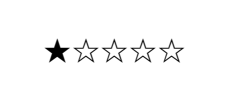 & $\begin{array}{l}\text { High } \\
\text { acceptance }\end{array}$ \\
\hline
\end{tabular}

Based on the above Analysis and Comparison of fatigue information collection Schemes, the following conclusions are drawn:

(1) The higher the dependence of fatigue information collection scheme on people, the less acceptable the user is;

(2) The fatigue information collection scheme is more difficult to change the vehicle, and the lesser the opportunity to put into practical use;

(3) Whether the fatigue information collection scheme is applicable or not is related to the accuracy and the total cost;

(4) The lower the dependence on people, the lower the total cost, the higher the accuracy of the scheme, and the more promising it is in practice.

Therefore, combined with the above conclusions, a fatigue driving state recognition scheme based on multi-source information fusion is proposed. The front-up camera collects eye position, frequency of blinks, frequency of glancing, staring time, and other indicators. The side camera collects the information of driver's head position and the steering angle sensor collects the steering wheel angle data.
This scheme has low dependence on the driver, less modification of the car, reasonable cost, and improved fatigue recognition.

\section{Analysis of fatigue driving state based on multi-source information fusion}

Referring to the existing research on fatigue driving, the driver's driving mental state is classified and defined separately. The driver's driving state is divided into five levels, which are the driver concentration, the driver distraction, the driver mild fatigue, the driver moderate fatigue and the driver deep fatigue.

When the driver's spirit is highly concentrated, the average eye blinks about 10-20 times per minute, the head moves within the normal range, and the percentage of nonsteering is $25 \%$. When the driver is distracted, the attention is dispersed by other things. His eyes are faint, his head swings slightly back and forth, left and right and the percentage of non-steering is $31 \%$.

PERCLOS refers to the proportion of time taken by the eye closure time. The $\mathrm{P} 80^{(16)}$ with high correlation with fatigue is selected to define the driver fatigue level. When the driver is mild mental fatigued, blinking 15 times per minute[21][28], PERCLOS is $5.4 \%-14.7 \%$, head tilt is 15 degrees, the percentage of non-steering is $38 \%$ and steering wheel angle standard deviation is 1.20 . When the driver was moderately fatigued, the PERCLOS is $14.7 \%-23.3 \%$, the head tilts 17.5 degrees back and forth, and the standard deviation of the steering wheel angle is 1.50. When the driver is in deep fatigue, eyes close for a long time, the PERCLOS is greater than $23.3 \%$, the pupil's brightness is significantly reduced, the head is tilted 20 degrees, and the standard deviation of the steering wheel angle is 1.81 .

In order to facilitate the research on active intervention of fatigue in the future, the driver's driving state is classified into five states: driver concentration, driver distraction, driver mild fatigue, driver moderate fatigue, driver deep fatigue. The parameters such as pupil characteristics, head tilt angle, and steering wheel characteristics of each state are also divided, as shown in Table 2. 
Table 2. Analys is of Fatigue Driving State Based on Multi-Source Information Fusion

\begin{tabular}{|c|c|c|c|}
\hline $\begin{array}{l}\text { Driving } \\
\text { condition }\end{array}$ & $\begin{array}{l}\text { Pupil } \\
\text { characteristics }^{(17)}\end{array}$ & Head feature $^{(18)}$ & $\begin{array}{l}\text { Ste ering wheel } \\
\text { feature }^{(19)}\end{array}$ \\
\hline $\begin{array}{l}\text { Driver } \\
\text { concentration }\end{array}$ & $\begin{array}{l}\text { Blinking about } \\
\text { 10-20 times per } \\
\text { minute }\end{array}$ & $\begin{array}{l}\text { Movement } \\
\text { within the } \\
\text { normal range of } \\
\text { the head }\end{array}$ & $\begin{array}{l}\text { The percentage of } \\
\text { non- steering is } \\
25 \%\end{array}$ \\
\hline $\begin{array}{l}\text { Driver } \\
\text { distraction }\end{array}$ & Distracted eyes & $\begin{array}{l}\text { Swinging } \\
\text { slightly back and } \\
\text { forth, left and } \\
\text { right }\end{array}$ & $\begin{array}{l}\text { The percentage of } \\
\text { non- steering is } \\
31 \%\end{array}$ \\
\hline $\begin{array}{l}\text { Driver mild } \\
\text { fatigue }\end{array}$ & $\begin{array}{l}\text { Blinking } 15 \text { times } \\
\text { per minute, } \\
\text { PERCLOS is } \\
5.4 \%-14.7 \%\end{array}$ & $\begin{array}{l}\text { Head tilts } 15 \\
\text { degrees }\end{array}$ & $\begin{array}{l}\text { The percentage of } \\
\text { non- steering is } \\
38 \% \text {, the standard } \\
\text { deviation of the } \\
\text { steering wheel } \\
\text { angle is } 1.20\end{array}$ \\
\hline $\begin{array}{l}\text { Driver } \\
\text { moderate } \\
\text { fatigue }\end{array}$ & $\begin{array}{l}\text { PERCLOS is } \\
14.7 \%-23.3 \%\end{array}$ & $\begin{array}{l}\text { Head tilts } 17.5 \\
\text { degrees }\end{array}$ & $\begin{array}{l}\text { The standard } \\
\text { deviation of the } \\
\text { steering wheel } \\
\text { angle is } 1.50\end{array}$ \\
\hline $\begin{array}{l}\text { Driver deep } \\
\text { fatigue }\end{array}$ & $\begin{array}{l}\text { Closing eyes for a } \\
\text { long time, } \\
\text { PERCLOSis } \\
\text { greater than } \\
23.3 \%\end{array}$ & $\begin{array}{l}\text { Head tilts } 20 \\
\text { degrees }\end{array}$ & $\begin{array}{l}\text { The standard } \\
\text { deviation of the } \\
\text { steering wheel } \\
\text { angle is } 1.81\end{array}$ \\
\hline
\end{tabular}

\section{Analysis of Test Schemes}

There are three kinds of driving fatigue experimental schemes, namely, the on-road experiment scheme, the simulation driving experiment scheme and the Virtual Reality (VR) experimental scheme.

In the on-road experimental scheme, the driver drives on the selected experimental road. Based on the characteristics of driver's pupil from the front-up camera, the information of driver's head position from the side camera, and the steering wheel angle data from the steering angle sensor, the driving state of the driver is discriminated. It is of high similarity of driver driving status while it is difficult to detect deep fatigue state with low security and high cost.

In the simulation driving experiment scheme the driver drives in the modified abandoned vehicle in front of the screen showing traffic information. Based on the characteristics of driver's pupil from the front-up camera, the information of driver's head position from the side camera, and the steering wheel angle data from the steering angle sensor, the driving state of the driver is discriminated. In the simulation driving experiment scheme, the driver does not travel on the road, so there is a slight gap between the driver's driving state and the driving state on the road. However, the cost is low and the deep fatigue state can be simulated.

In VR experimental scheme, the driver wears VR glasses with analog road condition information and sits in the car to simulate driving. Based on the characteristics of driver's pupil from the front-up camera, the information of driver's head position from the side camera, and the steering wheel angle data from the steering angle sensor, the driving state of the driver is discriminated. The cost is low and the deep fatigue state can be simulated. However, the driver's driving state has low similarity compared to the simulation driving experiment scheme.

Table 3. Comparis on of Test Schemes

\begin{tabular}{|c|c|c|c|}
\hline Test Scheme & $\begin{array}{c}\text { Similarity } \\
\text { of Driver } \\
\text { driving } \\
\text { status }\end{array}$ & Advantages & Disadvantages \\
\hline $\begin{array}{l}\text { The on-road } \\
\text { experiment } \\
\text { scheme }^{(20)}\end{array}$ & 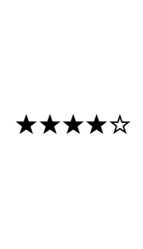 & $\begin{array}{l}\text { High Similarity } \\
\text { of Driver driving } \\
\text { status }\end{array}$ & $\begin{array}{l}\text { 1. high cost; } \\
\text { 2. Difficult to } \\
\text { detect deep } \\
\text { fatigue state with } \\
\text { low security }\end{array}$ \\
\hline $\begin{array}{l}\text { The simulation } \\
\text { driving } \\
\text { experiment } \\
\text { scheme }^{(21)}\end{array}$ & 太夫夫认约 & $\begin{array}{l}\text { 1. High cost; } \\
\text { 2. Can simulate } \\
\text { deep fatigue } \\
\text { state }\end{array}$ & $\begin{array}{l}\text { High Similarity } \\
\text { of Driver driving } \\
\text { status }\end{array}$ \\
\hline $\begin{array}{l}\text { VR } \\
\text { experimental } \\
\text { scheme }^{(22)}\end{array}$ & 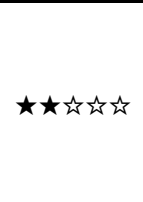 & $\begin{array}{l}\text { 1. High cost; } \\
\text { 2. Can simulate } \\
\text { deep fatigue } \\
\text { state }\end{array}$ & $\begin{array}{l}\text { High Similarity } \\
\text { of Driver driving } \\
\text { status }\end{array}$ \\
\hline
\end{tabular}

Based on comparison of test schemes, the simulation driving experiment scheme has low cost, high similarity with the driver's driving state, and can simulate deep fatigue state. So we choose this experimental scheme.

\section{Experimental platform for fatigue driving recognition}

(1) In the scrapped commercial vehicle, the steering 
angle sensor is installed in the steering column.

(2) Camera $\mathrm{A}$ is installed in the range of about 30 degrees in front of the driver's seat, and camera B is mounted on the side.

(3) The camera transmits the driver's driving status to the Advantech IPC-900 (Industrial Personal Computer) via 3.0 interface, 1.3 megapixels, 210 frames per second USB.

(4) IPC is installed outside the vehicle, and the C language is used for modeling and corresponding software programming to achieve driver fatigue recognition.

(5) The screen is placed 1 meter in front of the car to simulate driving scene and road conditions.

(6) The experimenter simulates the driver, sits in the driver's seat, and simulates the driver's fatigue state through changes in the pupil, head tilt, and steering wheel angle.

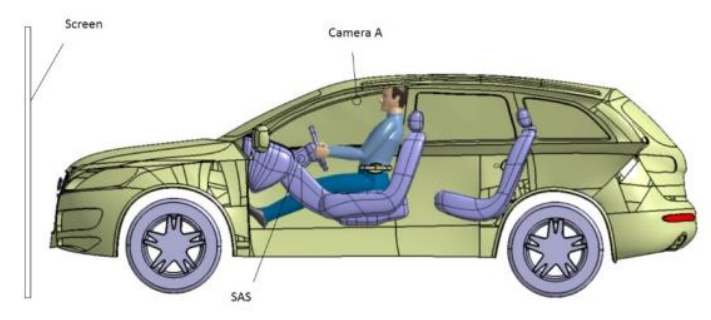

Fig. 1. Experimental platform A.

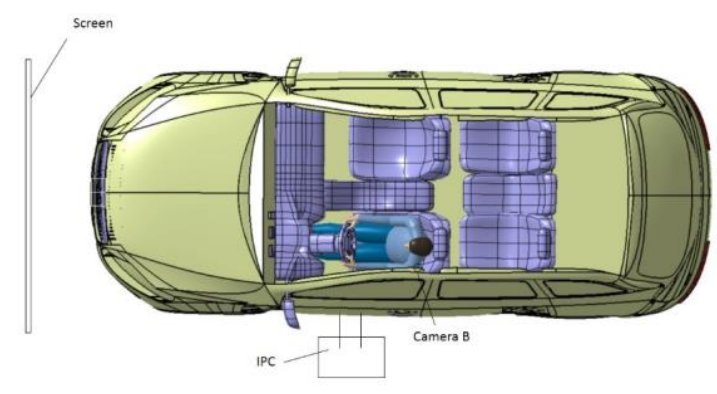

Fig. 2. Experimental platform B.

The front-up camera collects the characteristics of driver's pupil, the side camera collects the information of driver's head position and the steering angle sensor collects the steering wheel angle data. The camera and the sensor transmit the driving state to the IPC via USB in real time, and the IPC determines the driving state of the driver through the software.

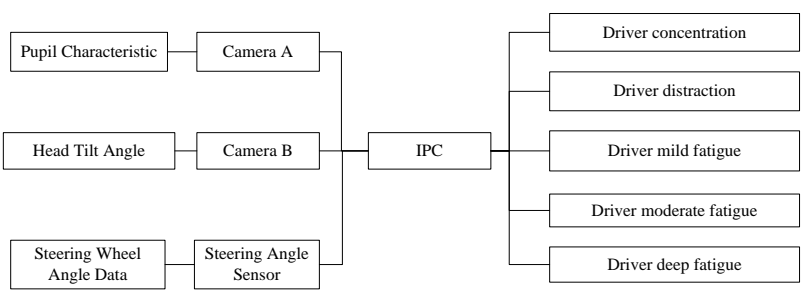

Fig. 3. System Principle Diagram.

\section{6. summary}

First, through the analysis and comparison of six fatigue information collection schemes, it is concluded that the lower the dependence on people, the lower the total cost, the higher the accuracy of the scheme, and the more promising it is in practice. And a fatigue driving state recognition scheme based on multi-source information fusion is proposed. The front-up camera collects eye position, frequency of blinks, frequency of glancing, staring time, and other indicators; The side camera collects the information of driver's head position; the steering angle sensor collects the steering wheel angle data.

Then the driver's driving state is classified into 5 levels, and each level of driving state is defined by multi-source information such as face expression features and steering wheel characteristics.

Finally, this paper compares the three experimental schemes of on-road experiment scheme, simulation driving experiment scheme and VR experimental scheme, and selects the simulation driving experiment scheme which has low cost, high driver's driving state fitting degree, and can simulate deep fatigue state. And the scheme of the experimental platform was proposed.

\section{References}

(1) Wang L, Pei Y : “ The impact of continuous driving time and rest time on commercial drivers' driving performance and recovery", Journal of Safety Research, Vol. 50, pp. 11-15, 2014

(2) May J F, Baldwin C L : "Driver fatigue : The importance of identifying causal factors of fatigue when considering detection and countermeasure technologies", Transportation Research Part F, Vol. 12, No. 3, pp. 218-224, 2009

(3) LT Zhi-chun, HE Ren, LIN Mou-you, LI Pei-lin : "Study Situation and Developing Trend on Detecting Technology of Motor Driver's Fatigue ", Journal of China Agricultural University(Social Sciences 
Edition), Vol. 6, No. 6, pp. 101-105, 2001

(4) LALS K I, CRAIG A : "A Critical Review of the Psychophysiology of Driver Fatigue", Biological Psychology, Vol. 55, No. 3, pp. 173-194, 2001

(5) Jap B T, Lal S, Fischer P, and Bekiaris E : "Using EEG spectral components to assess algorith ms for detecting fatigue " Expert Systems Application, Vo1. 36, No. 2, pp. 2352-2359, 2009

(6) Lal S K L, Craig A, Boord P, et al : "Development of an algorithm for an EEG-based driver fatigue countermeasure", Journal of Safely Research, Vol. 34, No. 3, pp. 321-328, 2003

(7) L. R. Hartley, P. K. Arnold, G Smythe, et al : "Indicators of fatigue in truck drivers ", Applied Ergonomics, Vol. 25, No. 3, pp. 143-156, 1994

(8) J. J. Furedy : "Beyond heart rate in the cardiac psycho physiological assessment of mental effort : the T-wave amplitude component of the electrocardiogram ", Human Factors, Vol. 29, No. 2, pp. 183-194, 1987

(9) Rosey F, Auberlet J M, Moisan O, et al : "Impact of Narrower Lane Width", Transportation Research Record : Journal of the Transportation Research Board, Vol. 2138, No. 1, pp. 112-119, 2009

(10) Auberlet J M, Rosey F, Anceaux F, et al : "The impact of perceptual treatments on driver's behavior : From driving simulator studies to field tests-First results ", Accident Analysis \& Prevention, Vol. 45, pp. 91-98, 2012

(11) Suzuki M, Yamamoto N, Yamamoto O, et al : "Measurement of driver's consciousness by image processing-A method for presuming driver's drowsiness by eye-blinks coping with individual differences", IEEE International Conference on Systems, Man and Cybernetics, Vol. 4, pp. 2891-2896, 2006

(12) FAN X, YIN B, SUN Y : "Yawning detection based on gabor wavelets and LDA", Journal of Beijing university of technology, Vol. 35, No. 3, pp. 409-413, 2009

(13) Satzoda R K, Trivedi M M : "Drive analysis using vehicle dynamics and vision-based lane semantics ", IEEE Transactions on Intelligent Transportation Systems, Vol. 16, No. 1, pp. 9-18, 2015

(14) ZHANG Xibo, CHENG Bo, FENG Ruijia : "Real-time detection of driver drowsiness based on steering performance", Journal of Tsinghua University(Science and Technology), Vol. 50, No. 7, pp. 1072-1076, 2010
(15) LI Shaowen, WANG Jiangbo : "Research on driver fatigue detection system. Computer Engineering and Applications", Vol. 49, No. 15, pp. 253-258, 2013

(16) Stern J A, Boyer D, Schroeder D : "Blink rate : a possible measure of fatigue", Human Factors, Vol. 36, No. 2, pp. 285, 1994

(17) XU Chuan, GUO Qiming, WANG Xuesong : " Driver Behavior Response to Drowsiness Alarming with Different Levels", Journal of Southwest Jiaotong University, http : //kns. cnki. net/kcms/detail/51. 1277. U. 20180708. 2241. 004. html, 2018

(18) Wen Fang : "Research on Fatigue Driving State Detection Based on SDM", Chang'an University, Degree-Master, Xi'an, China, 2018

(19) CHENG Bo, FENG Ruijia, ZHANG Wei, et al : "Driver Drowsiness Detection and Warning System Based on Multi-source Information Fusion", Journal of Highway and Transportation Research and Development, Vol. 26, No. S1, pp. 13-18, 2009

(20) LU Zhangping, YIN Chuanbin, LI Rui, et al : "Study of Driver's Fatigue Level Grading Experiment Based on His Physiological Signal", Journal of Chongqing Jiaotong University (natural science), Vol. 36, No. 1, pp. 77-81, 2017

(21) JIANG Zhao-Hui XIONG Jin WANG Xing-Jia, et al : "The Experimental Study on Driving Fatigue Based on Driving Simulator", CHINESE JOURNAL OF BIOMEDICAL ENGINEERING, Vol. 27, No. 6, pp. 832-837, 2008

(22) ZHANG Linxuan, XIN Xianjie, CUI Bing, et al : "Research on Automotive Product Design Oriented Virtual Reality Service Platform". JOURNAL OF SYSTEM SIMULATION, Vol. 26, No. 10, pp. 2407-2411, 2014 